\title{
The multiple relation theory and Schiffer's puzzle
}

\author{
Stefan Rinner ${ }^{1}[0$ \\ Received: 28 March 2019 / Accepted: 6 March 2020 / Published online: 17 March 2020 \\ (c) The Author(s) 2020
}

\begin{abstract}
Following Russell, philosophers like Moltmann, Jubien, Boër, and Newman analyse 'John believes that Mary is French' as ' $R$ (John, the property of being French, Mary)', instead of analysing it as ' $R$ (John, that Mary is French)'. Thus, for these philosophers, instead of relations holding between agents and truth-bearing entities (propositions), propositional attitude verbs, like 'belief', express relations holding between agents and the properties and objects our thoughts and speech acts are about. This is also known as the Multiple Relation Theory. In this paper, I will discuss the Multiple Relation Theory primarily in connection with a problem known as Schiffer's puzzle. Schiffer first presented the puzzle to argue against the so called direct-reference theory of belief reports advocated, among others, by Salmon and Braun. I will argue that, unlike the direct-reference theory of belief reports, the Multiple Relation Theory does not provide a solution to Schiffer's puzzle. In this connection, I will also discuss a slight modification of the Multiple Relation Theory according to which the ways the properties and objects our thoughts and speech acts are about are presented to us are part of the truth-conditions of sentences like 'John believes that Mary is French'. We will see that prima facie such a contextualist version of the Multiple Relation Theory provides a solution to Schiffer's puzzle. However, concluding, I will argue with new Schiffer cases that, ultimately, also a contextualist version of the Multiple Relation Theory cannot explain all instances of Schiffer's puzzle. This will undermine the Multiple Relation Theory in general.
\end{abstract}

Keywords The multiple relation theory $\cdot$ Schiffer's puzzle $\cdot$ De re belief $\cdot$ Proper names

Stefan Rinner

stefan.rinner@1rz.uni-muenchen.de

1 Ludwig Maximilian University of Munich (MCMP), Ludwigstr. 31, 80539 Munich, Germany 


\section{Introduction}

Following Russell (1912,1913, 1918), philosophers like Moltmann (2003, 2013, Chap. 4), Jubien (2001), Boër (2002), and Newman (2002) analyse (1) as (2a), instead of analysing (1) as $(2 b){ }^{1}$

(1) John believes that Mary is French.

(2a) $R$ (John, $\lambda x[x$ is French], Mary).

(2b) $R$ (John, that Mary is French).

Thus, for these philosophers, instead of relations holding between agents and truthbearing entities (propositions), propositional attitude verbs, like 'belief', express relations holding between agents and the properties and objects our thoughts and speech acts are about. For example, in (Moltmann 2003), Moltmann treats propositional attitude verbs, like 'belief' as syncategorematic expressions which, if, in the simplest case, the that-clause has a propositional content consisting of an $n$-place relation and $n$ arguments, will specify an $(n+2)$-place relation $R_{(b e l, n+2)}$ as in $(M)$ (Moltmann 2003, p. 94, pp. 96-97):

(M) For an $n$-place relation $R^{\prime}$ and entities $d_{1}, \ldots, d_{n}$, [believes, $\left\langle R^{\prime}, d_{1}, \ldots, d_{n}\right\rangle \rrbracket=\lambda x\left[R_{(b e l, n+2)}\left(x, R^{\prime}, d_{1}, \ldots, d_{n}\right)\right]$.

The claim that propositional attitude verbs, like 'belief', express relations holding between agents and the properties and objects our thoughts and speech acts are about is also known as the Multiple Relation Theory. ${ }^{2}$

There are various reasons why philosophers have advocated or still advocate the Multiple Relation Theory. For example, in (Moltmann 2003), Moltmann reintroduces the Multiple Relation Theory, among others, to explain that inferences like the inferences in (3) aren't logically valid.

3a. John remembers that Mary is French.

John remembers the proposition that Mary is French.

3b. John wishes that Mary is French.

John wishes the proposition that Mary is French.

\footnotetext{
1 Lebens (2017) advocates a Multiple Relation Theory for belief without advocating a Multiple Relation Theory for belief ascriptions; i.e. without analysing (1) as (2a). In this paper, my discussion of the Multiple Relation Theory will be restricted to the Multiple Relation Theory as a theory of belief ascriptions; i.e. to theories of belief ascriptions that analyse (1) as (2a). I would like to thank an anonymous reviewer for pointing this out to me.

2 An alternative to $(M)$ would be to say that propositional attitude verbs, like 'belief' are multigrade predicates (Moltmann 2013, Chap. 4). This requires the distinction between places and positions (cf. Oliver and Smiley 2004). For example, 'believe' would be a relation that has two places, and it would be multigrade in its second place. All this won't affect my discussion of the Multiple Relation Theory.

Note that Moltmann no longer holds that propositional attitude verbs, like 'belief' express relations holding between agents, properties, and objects. Instead, Moltmann analyses (1) as (2c), where 'believe' takes as its implicit Davidsonian event argument an act of believing, product is a function mapping that act onto its product, Ralph's belief, and [that Mary is French] is a property of such products, specifying their satisfaction conditions (Moltmann 2017).
}

(2c) $\exists e$ (believes $(e$, Ralph) \& [that Mary is French] (product $(e)))$.

For Moltmann's reasons to abandon the Multiple Relation Theory see (Moltmann 2017, App. 2). 
Since, according to the Relational Analysis, the premises in (3) are true if and only if John remembers/wishes the proposition that Mary is French, the Relational Analysis cannot explain this. According to Moltmann, this suggests that the premises in (3) have to be analysed as $(2 a)$, instead of analysing them as $(2 b)$. First of all, this would explain that the inferences in (3) aren't logically valid. Moreover, it would also explain that, unlike their conclusion, the premises of $(3 a)$ and $(3 b)$ specify the content of the attitude in question. Moltmann calls this 'the Objectivization Effect': Unlike the thatclause in the premises of (3), the complement in the conclusions of (3) "specifies not the mere content of the attitude, but the object the attitude is about or directed toward" (Moltmann 2003, p. 87).

Against the Multiple Relation Theory, it has been objected that what is judged or believed must be capable of being true or false. Since a collection of things, like the collection of Mary and the property of being happy, is not capable of being true or false, it has been concluded that the relata of the belief relation cannot be the properties and objects our thoughts and speech acts are about (see, for example, Hanks 2007, p. 140). Moltmann (2003, pp. 105-106) responds to this objection that attitude verbs, like 'belief', express modes of predication. For example, according to Moltmann, believing that Mary is happy is predicating, in the belief mode, the property of being happy of Mary. Since here predication is understood as an intentional act aiming at truth, according to Moltmann, the primary bearers of truth are not the relata of the belief relation, but the concrete acts of believing. ${ }^{3}$ In this way, an advocate of the Multiple Relation Theory could explain that beliefs are true or false without being committed to the claim that the objects of belief are truth-bearing entities.

In this paper, I won't go into detail about the different arguments for and against the Multiple Relation Theory that have been discussed in the literature. Instead, I will discuss the Multiple Relation Theory primarily in connection with a problem known as Schiffer's puzzle. Schiffer (2006) first presented the puzzle to argue against the so called direct-reference theory of belief reports advocated, among others, by Salmon (1986) and Braun (1998). I will argue that, unlike the direct-reference theory of belief reports, the Multiple Relation Theory does not provide a solution to Schiffer's puzzle. In this connection, I will also discuss a slight modification of the Multiple Relation Theory according to which the ways the properties and objects our thoughts and speech acts are about are presented to us are part of the truth-conditions of sentences like (1). We will see that prima facie such a contextualist version of the Multiple Relation Theory provides a solution to Schiffer's puzzle. However, concluding, I will argue with new Schiffer cases that, ultimately, also the contextualist version of the Multiple Relation Theory cannot explain all instances of Schiffer's puzzle. Together with the result that also the non-contextualist version of the Multiple Relation Theory, i.e. $(M)$, does not provide a solution to Schiffer's puzzle, this will undermine the Multiple Relation Theory in general.

The paper is structured as follows: In Sect. 2, I will argue that the Multiple Relation Theory is committed to what Schiffer calls 'the special-case consequence' and 'Frege's constraint'. Following this, in Sect. 3, I will argue with an example from

\footnotetext{
3 In chapter 12 of The Problems of Philosophy, Russell seems to hold a similar view, since he argues that a world of mere matter would only contain facts, but no truths or falsehoods. I would like to thank an anonymous reviewer for pointing this out to me.
} 
Schiffer that together with the special-case consequence and Frege's constraint the non-contextualist version of the Multiple Relation Theory, i.e. $(M)$, leads to contradictions. This is Schiffer's puzzle. In Sect. 4, I will argue that, unlike the direct-reference theory of belief reports, the non-contextualist version of the Multiple Relation Theory does not provide a solution to Schiffer's puzzle. Following this (Sect. 5), I will discuss a contextualist version of the Multiple Relation Theory, and I will argue with new Schiffer cases that, ultimately, also a contextualist version of the Multiple Relation Theory cannot solve Schiffer's puzzle.

\section{The special-case consequence and Frege's constraint}

The starting point of Schiffer's puzzle is a problem regarding de re belief which also arises within the Multiple Relation Theory. For example, both (4) and (5) can be true; e.g. if Ralph sincerely and reflectively utters both 'Karol Wojtyła is Polish' and 'It is not the case that John Paul II. is Polish'.

(4) Ralph believes that Karol Wojtyła is Polish.

(5) Ralph disbelieves ${ }^{4}$ that John Paul II. is Polish.

Moreover, it seems that according to the Multiple Relation Theory de re belief is simply a special case of de dicto belief. For example, if (4) is true, then, according to $(M)$, Ralph stands in the three-place belief relation $R_{(b e l, 3)}$ to the property of being Polish and Karol Wojtyła. ${ }^{5}$ Since this seems to be tantamount to saying that Karol Wojtyła

\footnotetext{
${ }^{4}$ Here 'disbelieve' is defined in terms of 'believe'. For example, to disbelieve that John Paul II. is Polish means to believe that it is not the case that John Paul II. is Polish. There are different ways to spell this out within the Multiple Relation Theory. For example, Moltmann (2003, p. 99) introduces proposition-like entities, so called attitudinal objects, in order to define 'believe' for connectives, like negation, conjunction, and disjunction. According to this account, connectives are predicates expressing properties of attitudinal objects or relations holding between attitudinal objects. Thus, if the that-clause has a propositional content consisting of a structured proposition and the property expressed by the negation-predicate, i.e. the property of being false, 'believe' will specify a three-place relation as in $M_{N e g}$, where $f\left(R_{e n t}, p, A\right)$ is an attitudinal object such that $f$ is a function taking the entertaining relation, $R_{e n t}$, a structured proposition $p$, and a kind of agent $A$ as arguments and returning there being an agent of kind $A$ standing in $R_{\text {ent }}$ to the constituents of $p$ :

$\left(M_{N e g}\right)$ For a structured proposition $p$, 【believes, $\langle\llbracket N e g \rrbracket, p\rangle \rrbracket=\left\{x \mid R_{(b e l, 3)}\left(x, \llbracket N e g \rrbracket, f\left(R_{e n t}, p, A\right)\right)\right\}$.
}

Following this, 'disbelieve' can be defined as follows, where $\left\langle\left\langle d_{1}, \ldots, d_{n}\right\rangle, R^{\prime}\right\rangle$ is the structured proposition consisting of the relation $R^{\prime}$ and the objects $d_{1}, \ldots, d_{n}$ :

$\left(M_{d i s}\right)$ (a) For an $n$-place relation $R^{\prime}$ and entities $d_{1}, \ldots, d_{n}$, $\llbracket$ disbelieves, $\left\langle R^{\prime}, d_{1}, \ldots, d_{n}\right\rangle \rrbracket=\lambda x\left[R_{(d i s, n+2)}\left(x, R^{\prime}, d_{1}, \ldots, d_{n}\right)\right]$.

(b) For an $n$-place relation $R^{\prime}$ and entities $d_{1}, \ldots, d_{n}$, $\lambda x\left[R_{(d i s, n+2)}\left(x, R^{\prime}, d_{1}, \ldots, d_{n}\right)\right]=\left\{x \mid R_{(\text {bel }, 3)}\left(x, \llbracket N e g \rrbracket, f\left(R_{e n t},\left\langle\left\langle d_{1}, \ldots, d_{n}\right\rangle, R^{\prime}\right\rangle, A\right)\right)\right\}$.

5 Strictly speaking, this presupposes that the propositional content of 'Karol Wojtyła is Polish' consists of the property of being Polish and Karol Wojtyła; i.e. that names are directly referential terms. Not all advocates of the Multiple Relation Theory accept this. For example, according to Jubien (2001), the relata of the belief relation are always properties and relations and never individuals. Something similar is true of Russell's original version of the Multiple Relation Theory. For example, according to Russell (1912), the 
is believed by Ralph to be someone such that he is Polish, the Multiple Relation Theory seems to be committed to what Schiffer (2006, p. 362) calls 'the special-case consequence':

The Special-Case Consequence $(S)$ : Necessarily, if $\alpha$ believes/disbelieves that $\phi_{\beta}$, then $\beta$ is believed/disbelieved by $\alpha$ to be (something/someone) such that $\phi_{\beta / i t}$.

Here $\alpha$ is any singular term of English, $\beta$ is any proper name or other directly referential term of English, $\phi_{i t}$ is any English open sentence in which the pronoun 'it' occurs as a free variable - alternatively 'he', 'she', 'him' or 'her' - and $\phi_{\beta}$ is the same as $\phi_{i t}$ except for having occurrences of $\beta$ wherever $\phi_{i t}$ has free occurrences of the relevant pronoun. If (4) and (5) are true, then, according to $(S)$, so are (6) and (7).

(6) Karol Wojtyła is believed by Ralph to be someone such that he is Polish.

(7) John Paul II. is disbelieved by Ralph to be someone such that he is Polish.

Since John Paul II. = Karol Wojtyła, and since we can simply assume that Ralph is both a brilliant logician, i.e. that he is in principle in a position to notice and correct contradictory beliefs, and fully rational, i.e. that he would never let contradictory beliefs pass if he recognises them as such, this leads to the question how a brilliant logician like Ralph can rationally both believe and disbelieve an object $o$ to be (something/someone) such that $\phi_{i t}$. I will call this 'the problem of rationality regarding de re belief'.

The received solution to the problem of rationality regarding de re belief says that Wojtyła is presented to Ralph by two modes of presentation $m$ and $m^{\prime}$ without him recognising that $m$ and $m^{\prime}$ are modes of presentation of one and the same person. Since Ralph believes Wojtyła to be Polish under $m$ and disbelieves Wojtyła to be Polish under $m^{\prime}$, the solution continues, Ralph cannot be convicted of irrationality. Schiffer calls this 'Frege's constraint' (Schiffer 2006, p. 362): ${ }^{6}$

$(F C)$ If an object $o$ is rationally both believed and disbelieved by an agent $k$ to be (something/someone) such that $\phi_{i t}$, then there are two modes of presentation $m$ and $m^{\prime}$ such that

(a) $o$ is believed by $k$ to be (something/someone) such that $\phi_{i t}$ under $m$,

(b) $o$ is disbelieved by $k$ to be (something/someone) such that $\phi_{i t}$ under $m^{\prime}$, and

(c) $k$ does not recognise that $m$ and $m^{\prime}$ are modes of presentation of one and the same object.

\section{Footnote 5 continued}

only directly referential terms are so called logically proper names; i.e. demonstratives like 'this' and 'that' which refer to sense-data or other objects of immediate acquaintance. Nowadays, however, most advocates of the Multiple Relation Theory would accept that the propositional content of 'Karol Wojtyła is Polish' consists of the property of being Polish and Karol Wojtyła; i.e. that, in addition to Russell's logically proper names, also ordinary proper names, like 'Karol Wojtyła' and 'John Paul II.', are directly referential terms. I will return to this later.

6 Frege's constraint leaves open what modes of presentation are, and what it is for $o$ to be believed by $k$ to be (something/someone) such that $\phi_{i t}$ under $m$. Rather, the notion of a mode of presentation is functionally defined by Frege's constraint; i.e. something is a mode of presentation if it plays the role defined by Frege's constraint. I will return to this later. 
Taken in its obvious intent, Frege's constraint appears to be a self-evident truth. If an agent $k$ rationally believes $o$ to be (something/someone) such that $\phi_{i t}$ and disbelieves $o^{\prime}$ to be (something/someone) such that $\phi_{i t}$, then, in so doing, $k$ takes $o$ and $o^{\prime}$ to be distinct. Insofar as $k$ is rational, he/she thereby takes $o$ and $o^{\prime}$ differently, even if, in fact, $o=o^{\prime}$. Thus, in addition to the special-case consequence, the Multiple Relation Theory also seems to be committed to Frege's constraint.

Following Frege's constraint, advocates of the Multiple Relation Theory have two options. First, they could claim that the modes of presentation implied by Frege's constraint are part of the truth-conditions of sentences like (4) and (5) and (6) and (7) (respectively). In this case, advocates of the Multiple Relation Theory would have to reject $(M)$, and, instead, hold something along the lines of $\left(M^{\prime}\right)$ (Moltmann 2003, p. 97). ${ }^{7}$

$\left(M^{\prime}\right)$ For an $n$-place relation $R^{\prime}$, entities $d_{1}, \ldots, d_{n}$ and (types of) modes of presentation $T^{\prime}, T_{1}, \ldots, T_{n}$,

【believes/disbelieves, $\left\langle\left\langle R^{\prime}, T^{\prime}\right\rangle,\left\langle d_{1}, T_{1}\right\rangle, \ldots,\left\langle d_{n}, T_{n}\right\rangle\right\rangle \rrbracket$

$=\lambda x\left[R_{(\text {bel } / \text { dis }, n+2)}\left(x,\left\langle R^{\prime}, T^{\prime}\right\rangle,\left\langle d_{1}, T_{1}\right\rangle, \ldots,\left\langle d_{n}, T_{n}\right\rangle\right)\right]{ }^{8}$

7 As Moltmann $(2003$, p. 98) rightly points out, this is a deviation from the spirit of Russell's original
analysis, since Russell's aim was to avoid modes of presentation. Moreover, one could object that according
to $\left(M^{\prime}\right)$ the relata of the belief relation are pseudo entities, i.e. ordered pairs consisting of objects and modes
of presentation. Thus, the objection goes, according to $\left(M^{\prime}\right)$. John's believing that Mary is French is not a
way the world is or might be, but rather a technical artifact. An advocate of the Multiple Relation Theory
could respond that there are other ways to claim that the modes of presentation implied by Frege's constraint
are part of the truth-conditions of sentences like (4) and (5) and (6) and (7). For example, an advocate of
the Multiple Relation Theory could hold something along the lines of $\left(M^{\prime \prime}\right)$ :
$\left(M^{\prime \prime}\right)$ For an $n$-place relation $R^{\prime}$, entities $d_{1}, \ldots, d_{n}$ and (types of) modes of presentation $T^{\prime}, T_{1}, \ldots, T_{n}$,
$\llbracket$ believes/disbelieves, $\left\langle R^{\prime}, d_{1}, \ldots, d_{n}, T^{\prime}, T_{1}, \ldots, T_{n}\right\rangle \rrbracket=\lambda x\left[R_{(b e l} / d i s, 2 n+3\right)\left(x, R^{\prime}, d_{1}, \ldots, d_{n}\right.$,
$\left.\left.T^{\prime}, T_{1}, \ldots, T_{n}\right)\right]$.

According to this version of the Multiple Relation Theory, (1) has to be analysed as (2d), where $T$ is a mode of presentation of the property of being French and $T^{\prime}$ is a mode of presentation of Mary:

(2d) $R_{(b e l, 5)}($ John, $\lambda x[x$ is French], Mary, T, T')

(2d) could then be read as John believes that Mary is French under $T$ and $T^{\prime}$, where the relata of the belief relation are not pseudo entities anymore, but objects, properties/relations, and modes of presentation of objects and properties/relations. Nevertheless, in what follows, I will discuss $\left(M^{\prime}\right)$ as an alternative to $(M)$, since this won't affect my discussion of the Multiple Relation Theory. I would like to thank an anonymous reviewer for pointing this objection to $\left(M^{\prime}\right)$ out.

${ }^{8}$ Again, 'disbelieve' has to be defined in terms of 'believe' by first defining 'believe' for negation as in $M_{N e g}^{\prime}$, where $T$ is a mode of presentation of the structured proposition $p$ :

$\left(M_{N e g}^{\prime}\right)$ For a structured proposition $p$ and a (type of) mode of presentation $T$, 【believes, $\langle\llbracket N e g \rrbracket,\langle p, T\rangle\rangle \rrbracket=\left\{x \mid R_{(b e l, 3)}\left(x, \llbracket N e g \rrbracket,\left\langle f\left(R_{e n t}, p, A\right), T\right\rangle\right)\right\}$.

Following this, $R_{(d i s, n+2)}$ can be defined as follows, where $\left\langle\left\langle d_{1}, \ldots, d_{n}\right\rangle, R^{\prime}\right\rangle$ is again the structured proposition consisting of the relation $R^{\prime}$ and the objects $d_{1}, \ldots, d_{n}$, and $\left\langle\left\langle T_{1}, \ldots, T_{n}\right\rangle, T^{\prime}\right\rangle$ is a mode of presentation of this structured proposition consisting of modes of presentations of its parts:

$\left(M_{d i s}^{\prime}\right.$ ) For an $n$-place relation $R^{\prime}$, entities $d_{1}, \ldots, d_{n}$ and (types of) modes of presentation $T^{\prime}$, $T_{1}, \ldots, T_{n}$,

$\lambda x\left[R_{(\text {dis }, n+2)}\left(x,\left\langle R^{\prime}, T^{\prime}\right\rangle,\left\langle d_{1}, T_{1}\right\rangle, \ldots,\left\langle d_{n}, T_{n}\right\rangle\right)\right]$ $=\left\{x \mid R_{(b e l, 3)}\left(x, \llbracket N e g \rrbracket,\left\langle f\left(R_{\text {ent }},\left\langle\left\langle d_{1}, \ldots, d_{n}\right\rangle, R^{\prime}\right\rangle, A\right),\left\langle\left\langle T_{1}, \ldots, T_{n}\right\rangle, T^{\prime}\right\rangle\right\rangle\right)\right\}$. 
The second option is to stick with $(M)$, and, thus, to claim that the modes of presentation implied by Frege's constraint are not part of the truth-conditions of sentences like (4) and (5) and (6) and (7) (respectively). Nevertheless, just like $\left(M^{\prime}\right),(M)$ is consistent with Frege's constraint. For example, an advocate of $(M)$ could claim that $R_{(b e l, n+2)}$ is the existential generalization of a relation $R_{(b e l, n+2)}^{\prime}$ involving the modes of presentation implied by Frege's constraint; i.e. that for all $x: R_{(b e l, n+2)}\left(x, R^{\prime}, d_{1}, \ldots, d_{n}\right)$ if and only if there are (types of) modes of presentation $T^{\prime}, T_{1}, \ldots, T_{n}$ such that $R_{(b e l, n+2)}^{\prime}\left(x,\left\langle R^{\prime}, T^{\prime}\right\rangle,\left\langle d_{1}, T_{1}\right\rangle, \ldots,\left\langle d_{n}, T_{n}\right\rangle\right) .{ }^{9}$ In this way, $(M)$ would provide a solution to the problem of rationality regarding de re belief via Frege's constraint without being committed to the claim that the modes of presentation implied by Frege's constraint are part of the truth-conditions of sentences like (4) and (5) and (6) and (7) (respectively).

Although both $(M)$ and $\left(M^{\prime}\right)$ can explain how (4) and (5) can be true of a brilliant and fully rational logician like Ralph, unlike $(M),\left(M^{\prime}\right)$ could also explain that there can be circumstances in which (4) is true and (8) is false.

(4) Ralph believes that Karol Wojtyła is Polish.

(8) Ralph believes that John Paul II. is Polish.

For example, if Ralph is disposed to sincerely and reflectively utter 'Karol Wojtyła is Polish' without being disposed to sincerely and reflectively utter 'John Paul II. is Polish', we have strong intuitions that (4) is true and (8) is false. However, since, according to $(M)$, both (4) and (8) have the logical form in (9), $(M)$ could not explain this.

(9) $R_{(b e l, 3)}$ (Ralph, $\lambda x[x$ is Polish], Karol Wojtyła).

This is also known as Frege's puzzle.

In (Moltmann 2003, p. 97), Moltmann solves Frege's puzzle by replacing $(M)$ with $\left(M^{\prime}\right)$. For example, according to $\left(M^{\prime}\right)$, (4) has to be analysed as (10), and (8) has to be analysed as (11), where $T_{K W}$ and $T_{K W}^{\prime}$ are two distinct (contextually determined) (types of) modes of presentation of Karol Wojtyła, and $T_{P o l}$ is a (contextually determined) (type of) mode of presentation of the property of being Polish.

(10) $R_{(b e l, 3)}$ (Ralph, $\left\langle\lambda x\left[x\right.\right.$ is Polish], $\left.T_{P o l}\right\rangle,\left\langle\right.$ Karol Wojtyła, $\left.T_{K W}\right\rangle$ ).

(11) $R_{(b e l, 3)}$ (Ralph, $\left\langle\lambda x\left[x\right.\right.$ is Polish], $\left.T_{P o l}\right\rangle$, $\left\langle\right.$ Karol Wojtyła, $\left.T_{K W}^{\prime}\right\rangle$ ).

Since there can be circumstances in which (10) is true and (11) is false, in this way, an advocate of the Multiple Relation Theory could explain how there can be circumstances in which (4) is true and (8) is false. Such a solution to Frege's puzzle is also called a 'contextualist solution to Frege's puzzle'. Therefore, I will call $\left(M^{\prime}\right)$ 'the contextualist version of the Multiple Relation Theory'. ${ }^{10}$

\footnotetext{
${ }^{9}$ See for example (Salmon 1986) for a discussion of a similar theory of belief in connection with the direct-reference theory of belief reports. There Salmon claims that the two-place belief relation holding between agents and Russellian propositions is the existential generalization of a three-place belief relation holding between agents, Russellian propositions, and propositional modes of presentation; i.e. that an agent $x$ believes a proposition $p$ if and only if there is a mode of presentation $m$ of $p$ such that $x$ believes $p$ under $m$.

${ }^{10}$ Note that also a contextualist version of the Multiple Relation Theory could explain that the inferences in (3) aren't logically valid. Since, just like the RelationalAnalysis, a contextualist version of the Relational
} 
The alternative to a contextualist solution to Frege's puzzle is a naive solution to Frege's puzzle. According to a naive solution to Frege's puzzle, (4) is true if and only if (8) is true; i.e. according to a naive solution to Frege's puzzle, our intuitions regarding the truth-values of sentences like (4) and (8) can be misleading (see, for example, Salmon 1986; Braun 1998). Following this, a naive solution to Frege's puzzle has to provide an explanation of how our intuitions regarding the truth-values of sentences like (4) and (8) can be misleading. Here an advocate of $(M)$ could build on Salmon's (1986) or Braun's (1998) naive solution to Frege's puzzle in connection with the directreference theory of belief reports. Therefore, I will call $(M)$ also 'the naive version of the Multiple Relation Theory'.

The discussion between the naive and the contextualist version of the Multiple Relation Theory can be compared with the discussion between the naive version of the direct-reference theory of belief reports advocated by Salmon (1986) and Braun (1998) and the contextualist version of the direct-reference theory of belief reports advocated by Crimmins and Perry (1989) and Crimmins (1992). A contextualist theory has the advantage that it can take our intuitions regarding the truth-values of sentences like (4) and (8) seriously, whereas a naive theory has the advantage that it does not have to introduce modes of presentation as unarticulated constituents; i.e. contents for which no word or morpheme in the sentence stands for. Therefore, just like in connection with the direct-reference theory of belief reports, prima facie, also in connection with the Multiple Relation Theory both a naive and a contextualist version of the theory seem to be serious options. However, in the next section, I will argue with an example from Schiffer that together with the special-case consequence and Frege's constraint the naive version of the Multiple Relation Theory leads to contradictions. Since, as we have seen above, the naive version of the Multiple Relation Theory seems to be committed to both the special-case consequence and Frege's constraint, this will undermine the naive version of the Multiple Relation Theory. We will see that, prima facie, the same problem does not arise in connection with the contextualist version of the Multiple Relation Theory.

\section{Schiffer's puzzle}

Take the above example of Ralph. From Ralph's sincere and reflective utterance of 'Karol Wojtyła is Polish' and 'It is not the case that John Paul II. is Polish' we infer that both (4) and (5) are true. This means that we presuppose the following disquotational principles connecting sincere assertion and belief, where ' $p$ ' can be replaced, inside and outside quotation marks, by any standard English sentence lacking indexical or pronominal devices or ambiguities (Kripke 1979, pp. 248-249) ${ }^{11}$ :

\footnotetext{
Footnote 10 continued

Analysis, like Crimmins and Perry's theory (1989) and Crimmins (1992), has difficulties in explaining this, the Objectivization Effect would also be a reason to prefer a contextualist version of the Multiple Relation Theory to a contextualist version of the Relational Analysis.

11 Sentences containing indexical or pronominal devices are excluded, since, for example, from Ralph's sincere, reflective utterance of 'I am hungry' it does not follow that he believes that I (the author) am hungry (Kripke 1979, p. 249).
} 
$(D P)$ If a normal English speaker sincerely and reflectively utters ' $p$ ', then he/she believes that $p$.

$\left(D P^{\prime}\right)$ If a normal English speaker sincerely and reflectively utters 'It is not the case that $p^{\prime}$, then he/she disbelieves that $p .^{12}$

Analogous principles can be formulated for French, German etc.

Taken in their obvious intent, also $(D P)$ and $\left(D P^{\prime}\right)$ seem to be self-evident truths. In particular, $(D P)$ and $\left(D P^{\prime}\right)$ seem to be true of belief ascriptions of the form ' $A$ believes that $S$ '. For example, if a normal English speaker sincerely and reflectively utters 'Ralph believes that snow is white', we usually infer that the speaker believes that Ralph believes that snow is white. Similarly, if a normal English speaker sincerely and reflectively utters 'It is not the case that Ralph believes that snow is white', we usually infer that the speaker disbelieves that Ralph believes that snow is white. ${ }^{13}$

Now, Schiffer (2006, p. 363) notes that in the example of Ralph even a rational, normal English speaker who knows that 'Karol Wojtyła = John Paul II.' is true could sincerely and reflectively utter both (4) and (12); e.g. if the speaker has Fregean intuitions regarding the truth-values of sentences like (4) and (12).

(4) Ralph believes that Karol Wojtyła is Polish.

(12) It is not the case that Ralph believes that John Paul II. is Polish.

Assume that Peter is such a speaker. Together with $(D P)$ and $\left(D P^{\prime}\right)$, it would follow that both (13) and (14) are true.

(13) Peter believes that Ralph believes that Karol Wojtyła is Polish.

(14) Peter disbelieves that Ralph believes that John Paul II. is Polish.

If (13) and (14) are true, then, according to $(S)$, so are (15) and (16).

(15) Karol Wojtyła is believed by Peter to be someone such that Ralph believes that he is Polish.

12 Note that $\left(D P^{\prime}\right)$ follows from $(D P)$ and the fact that to disbelieve that $p$ means to believe that it is not the case that $p$, since the following principle is simply an instance of $(D P)$, where ' $p$ ' is again restricted to standard English sentences lacking indexical or pronominal devices or ambiguities:

$\left(D P^{*}\right)$ If a normal English speaker sincerely and reflectively utters 'It is not the case that $p$ ', then he/she believes that it is note the case that $p$.

13 One could object that we usually also infer that a speaker does not believe that John Paul II. is Polish if the speaker is not disposed to sincerely and reflectively utter 'John Paul II. is Polish'. Nevertheless, so called Naive Russellians, like Salmon (1986) and Braun (1998), have questioned the disquotational principle we seem to invoke when we make such inferences:

$(S D P)$ If a normal English speaker is not disposed to sincerely and reflectively utter ' $p$ ', then he/she does not believe that $p$.

This is certainly related to Salmon's and Braun's claim that our intuitions regarding the truth-values of sentences like (4) and (8) can be misleading. However, even philosophers like Salmon and Braun who question our intuitions regarding the truth-values of sentences like (4) and (8) do not question $(D P)$ or $\left(D P^{\prime}\right)$. They only question $(S D P)$. Salmon (2011) even argues that principles like $(D P)$ and $\left(D P^{\prime}\right)$ are virtually analytic; i.e. that every instance of the principles is true by virtue of pure semantics. Moreover, even if our intuitions regarding the truth-values of sentences like (4) and (8) were misleading, it would not follow that we have to reject $(D P)$ or $\left(D P^{\prime}\right)$ for belief ascriptions like (4) and (8) or their negation. It would only follow that the inferred beliefs can be false. 
(16) John Paul II. is disbelieved by Peter to be someone such that Ralph believes that he is Polish.

According to $(M),(15)$ then has the logical form in (17), and (16) has the logical form in (18), where $B E L$ stands for the three-place predicate ' $x$ is believed by $y$ to be someone/something such that $\phi_{i t}$ ' and DIS stands for the three-place predicate ' $x$ is disbelieved by $y$ to be someone/something such that $\phi_{i t}{ }^{\prime}:{ }^{14}$

(17) $B E L$ (Karol Wojtyła, Peter, $\lambda z\left[R_{(b e l, 3)}(\right.$ Ralph, $\lambda x[x$ is Polish $\left.\left.], z)\right]\right)$.

(18) $D I S$ (Karol Wojtyła, Peter, $\lambda z\left[R_{(b e l, 3)}(\right.$ Ralph, $\lambda x[x$ is Polish $\left.], z)\right]$ ).

From this, in turn, it would follow together with Frege's constraint that Karol Wojtyła is presented to Peter by two modes of presentation without him recognising that these are modes of presentation of one and the same person. However, since Peter believes 'Karol Wojtyła = John Paul II.' to be true, we can simply assume that Wojtyła is not presented to Peter by two modes of presentation without him recognising that these are modes of presentation of one and the same person. This is Schiffer's puzzle.

Schiffer's puzzle shows that together with the special-case consequence the naive version of the Multiple Relation Theory, i.e. $(M)$, leads to instances of the problem of rationality regarding de re belief that violate Frege's constraint. Together with the claim that the naive version of the Multiple Relation Theory is committed to both the special-case consequence and Frege's constraint, this would refute the naive version of the Multiple Relation Theory.

Prima facie, the same problem does not arise in connection with the contextualist version of the Multiple Relation Theory. Even if Peter does not have two modes of presentation of Karol Wojtyła, he could still attribute two such modes of presentation to Ralph. In this case, according to $\left(M^{\prime}\right),(15)$ would have the logical form in (19), and (16) would have the logical form in (20), where $T_{K W}$ and $T_{K W}^{\prime}$ are the modes of presentation of Karol Wojtyła that Peter attributes to Ralph.

(19) $B E L$ (Karol Wojtyła, Peter, $\lambda z\left[R_{(b e l, 3)}\left(\right.\right.$ Ralph, $\left\langle\lambda x[x\right.$ is Polish $\left.], T_{P o l}\right\rangle,\langle z$, $\left.\left.\left.\left.T_{K W}\right\rangle\right)\right]\right)$.

(20) DIS (Karol Wojtyła, Peter, $\lambda z\left[R_{(b e l, 3)}\right.$ (Ralph, $\left\langle\lambda x[x\right.$ is Polish $\left.], T_{P o l}\right\rangle,\langle z$, $\left.\left.\left.\left.T_{K W}^{\prime}\right\rangle\right)\right]\right)$.

Now, according to (19) and (20), Karol Wojtyła is not both believed and disbelieved by Peter to be someone Ralph believes to be Polish, but rather he is believed by Peter to be someone Ralph believes under $T_{K W}$ to be Polish, and disbelieved by Peter to be someone Ralph believes under $T_{K W}^{\prime}$ to be Polish. Since from this it does not follow together with Frege's constraint that Karol Wojtyła is presented to Peter by two modes of presentation without him recognising that these are modes of presentation of one

\footnotetext{
14 Note that although it is very likely that in the above example Peter attributes two modes of presentation of Karol Wojtyła to Ralph, according to $(M)$, these modes of presentation are not part of the truth-conditions of sentences like (13) and (14) and (15) and (16) (respectively). For example, according to (M), both the embedded sentence of (13) and the embedded sentence of (14) have the logical form in (9):
}

(9) $R_{(b e l, 3)}$ (Ralph, $\lambda x[x$ is Polish], Karol Wojtyła).

Although Russell does not discuss embedded cases, there is no in-principle obstacle to extending the Multiple Relation Theory to such cases. I would like to thank an anonymous reviewer for pointing this out to me. 
and the same person, prima facie, the contextualist version of the Multiple Relation Theory provides a solution to Schiffer's puzzle.

In Sect. 5, I will discuss such a contextualist solution to Schiffer's puzzle in more detail. But first I will briefly discuss the possibility to reject the special-case consequence or Frege's constraint within the naive version of the Multiple Relation Theory. For example, in (Salmon 2006), Salmon replies to Schiffer's objection that the directreference theory of belief reports is not committed to $(S)$, but to counter-instances of $(S)$. Therefore, next, I will briefly present Schiffer's puzzle in connection with the direct-reference theory of belief reports. Following this, I will argue that, unlike the direct-reference theory of belief reports, the naive version of the Multiple Relation Theory cannot solve Schiffer's puzzle by rejecting the special-case consequence or Frege's constraint.

\section{Rejecting the special-case consequence or Frege's constraint}

As said above, Schiffer first presented his puzzle as an objection to the so called direct-reference theory of belief reports. For example, following the work of Marcus (1961), Donnellan (1970), Perry (1977), Kripke (1980) and Kaplan (1989), so called Neo-Russellians, like Salmon (1986) and Braun (1998), hold that:

$\left(N R_{1}\right)$ The propositions we say and believe are Russellian propositions; i.e. structured propositions whose basic components are the objects and properties our thoughts and speech acts are about.

$\left(N R_{2}\right)$ Names and other singular terms (pronouns, simple demonstratives, indexicals) function as directly referential terms; i.e. the semantic content of ' $n$ is $F$ ' in a context $c$ is the singular proposition $\langle o, \Phi\rangle$, where $o$ is the referent of the name $n$ in $c$ and $\Phi$ is the property expressed by the predicate $F$ in $c$.

This is also known as the direct-reference theory. ${ }^{15}$ Moreover, Salmon and Braun advocate the following theory of belief reports:

$\left(N R_{3}\right)$ A sentence of the form ' $n$ believes/disbelieves that $S$ ' is true in a context $c$ iff the referent of the name $n$ in $c$ believes/disbelieves the proposition expressed by the sentence $S$ in $c .{ }^{16}$

Since the theory consisting of $\left(N R_{1}\right),\left(N R_{2}\right)$, and $\left(N R_{3}\right)$ is committed to a naive solution to Frege's puzzle according to which our intuitions regarding the truth-values of sentences like (4) and (8) can be misleading, it is sometimes referred to as 'the naive version of the direct-reference theory of belief reports'. ${ }^{17}$

\footnotetext{
15 As the name suggests, just like the Multiple Relation Theory, the Neo-Russellian theory also goes back to Russell (1905, 1910-1911, 1912). However, according to Russell, the only directly referential terms are so called logically proper names; i.e. demonstratives like 'this' and 'that' which refer to sense-data or other objects of immediate acquaintance.

16 Here to disbelieve a proposition $p$ means to believe its negation.

17 Not all direct-reference theorists accept $\left(N R_{3}\right)$. For example, Crimmins and Perry (1989) and Crimmins (1992) hold that 'believe' expresses a three-place relation holding between agents, Russellian propositions and contextually determined modes of presentation. This is also known as 'the contextualist version of the direct-reference theory of belief reports', since it provides a contextualist solution to Frege's puzzle according to which there can be circumstances in which (4) is true and (8) is false.
} 
In (Schiffer 2006), Schiffer argues that the naive version of the direct-reference theory of belief reports is committed to both the special-case consequence and Frege's constraint. For example, according to the naive version of the direct-reference theory of belief reports, to believe of an object $x$, de re, that it is $F$ simply seems to be to believe de dicto the singular proposition about $x$ that it is $F$. Therefore, according to Schiffer, also within the naive version of the direct-reference theory of belief reports the inferences from (13) and (14) to (15) and (16) are valid. Moreover, according to the naive version of the direct-reference theory of belief reports, (15) has the logical form in (21), and (16) has the logical form in (22), where $B$ stands for the two-place belief relation holding between agents and Russellian propositions.

(21) $B E L$ (Karol Wojtyła, Peter, $\lambda z[B$ (Ralph, that $z$ is Polish)]).

(22) DIS (Karol Wojtyła, Peter, $\lambda z[B$ (Ralph, that $z$ is Polish) $]$ ).

Since from this it would follow together with Frege's constraint that Karol Wojtyła is presented to Peter by two modes of presentation without him recognising that these are modes of presentation of one and the same person, we see that together with the special-case consequence also the naive version of the direct-reference theory of belief reports leads to instances of the problem of rationality regarding de re belief that violate Frege's constraint. Thus, if the naive version of the direct-reference theory of belief reports were committed to both the special-case consequence and Frege's constraint, this would refute the naive version of the direct reference theory of belief reports. ${ }^{18}$

In (Salmon 2006, pp. 271-272), Salmon replies to Schiffer's objection that the naive version of the direct-reference theory of belief reports is not committed to $(S)$, but to counter-instances of $(S)$. Braun (2006, p. 376) agrees with Salmon on this point. As Salmon (2006, pp. 271-272) rightly points out, within the naive version of the directreference theory of belief reports, one example of a counter-instance of $(S)$ is provided by Schiffer's puzzle itself. If (13) and (14) are true, then, according to the naive version of the direct-reference theory of belief reports, Peter both believes and disbelieves the singular proposition 〈〈Ralph, 〈Karol Wojtyła, being Polish $\rangle$, believing $\rangle$. However, Peter does not thereby both believe and disbelieve the singular proposition $\langle$ Karol Wojtyła, being (someone) such that Ralph believes that he is Polish $\rangle$. For example, if Peter believes 'Karol Wojtyła = John Paul II.' to be true, then, as a rational, normal English speaker, he is not disposed to sincerely and reflectively utter both (25) and (26).

(25) Karol Wojtyła is (someone) such that Ralph believes that he is Polish.

(26) It is not the case that John Paul II. is (someone) such that Ralph believes that he is Polish.

Since, according to the naive version of the direct-reference theory of belief reports, (15) is true if and only if Peter believes the singular proposition 〈Karol Wojtyła, being

\footnotetext{
18 Note that Schiffer's puzzle is not a problem for the contextualist version of the direct-reference theory of belief reports, since, according to Crimmins and Perry, (15) has the logical form in (23), and (16) has the logical form in (24), where $m$ and $m^{\prime}$ are two (contextually determined) modes of presentation of the singular proposition that Karol Wojtyła is Polish that Peter attributes to Ralph.
}

(23) $B E L$ (Karol Wojtyła, Peter, $\lambda z[B$ (Ralph, that $z$ is Polish, $m$ ) ]).

(24) DIS (Karol Wojtyła, Peter, $\lambda z\left[B\right.$ (Ralph, that $z$ is Polish, $\left.\left.m^{\prime}\right)\right]$ ). 
(someone) such that Ralph believes that he is Polish〉, and (16) is true if and only if Peter disbelieves $\langle$ Karol Wojtyła, being (someone) such that Ralph believes that he is Polish $\rangle$, it follows that although, in the above example, both (13) and (14) are true, according to the naive version of the direct-reference theory of belief reports, (15) or (16) is not.

This leads to the question whether a similar solution to Schiffer's puzzle is also available within the naive version of the Multiple Relation Theory. I will argue that it is not. According to $(M)$, both the propositional content of (4) and the propositional content of (8) consist of the three-place belief relation $R_{(b e l, 3)}$, Ralph, the property of being Polish, and Karol Wojtyła. From this, in turn, it follows within the naive version of the Multiple Relation Theory that (13) has the logical form in (27), and that (14) has the logical form in (28).

(27) $R_{(b e l, 5)}$ (Peter, $\lambda x \lambda y \lambda z\left[R_{(b e l, 3)}(x, y, z)\right]$, Ralph, $\lambda x[x$ is Polish], Karol Wojtyła).

(28) $R_{(d i s, 5)}\left(\right.$ Peter, $\lambda x \lambda y \lambda z\left[R_{(b e l, 3)}(x, y, z)\right]$, Ralph, $\lambda x[x$ is Polish], Karol Wojtyła).

Since this seems to be tantamount to saying that Karol Wojtyła is both believed and disbelieved by Peter to be believed by Ralph to be Polish, it is very likely that within the naive version of the Multiple Relation Theory Schiffer's puzzle does not provide a counter-instance of the special-case consequence. This suggests that, unlike the naive version of the direct-reference theory of belief reports, the naive version of the Multiple Relation Theory leads to instances of the problem of rationality regarding de re belief that violate Frege's constraint.

If the naive version of the Multiple Relation Theory leads to instances of the problem of rationality regarding de re belief that violate Frege's constraint, then we have to reject the naive version of the Multiple Relation Theory or Frege's constraint. In (Schiffer 2006, pp. 364-365), Schiffer notes that, prima facie, an advocate of the naive version of the direct-reference theory of belief reports could solve his puzzle by rejecting Frege's constraint. For example, in order to explain that a brilliant logician like Ralph can rationally both believe and disbelieve the singular proposition /Karol Wojtyła, being Polish $\rangle$, advocates of the naive version of the direct-reference theory of belief reports already accept a version of Frege's constraint for propositional modes of presentation; i.e. Salmon's constraint (see, for example, Salmon 1986).

$(S C)$ If a proposition $p$ is rationally both believed and disbelieved by an agent $k$, then there are modes of presentation $m$ and $m^{\prime}$ such that

(a) $p$ is believed by $k$ under $m$,

(b) $p$ is disbelieved by $k$ under $m^{\prime}$, and

(c) $k$ does not take $m$ and $m^{\prime}$ to be modes of presentation of one and the same proposition.

Following this, Schiffer notes that an advocate of the naive version of the directreference theory of belief reports could respond to his objection that although Karol Wojtyła is not presented to Peter by two modes of presentation without him recognising that these are modes of presentation of one and the same person, the singular proposition 〈〈Ralph, 〈Karol Wojtyła, being Polish $\rangle\rangle$, believing $\rangle$ is nevertheless presented 
to him by two modes of presentation without him recognising that these are modes of presentation of one and the same proposition. Since Peter believes the proposition under one mode of presentation and disbelieves it under the other, the solution goes, Peter cannot be convicted of irrationality. However, Schiffer (2006, p. 365) also notes that it is very unclear how to construe the propositional modes of presentation implied by Salmon's constraint such that Salmon's constraint does not commit the naive version of the direct-reference theory of belief reports to Frege's constraint. Moreover, such a solution to Schiffer's puzzle is not even available within the naive version of the Multiple Relation Theory. According to the naive version of the Multiple Relation Theory, the belief relation holding between agents, properties/relations, and objects is not reducible to a belief relation holding between agents and Russellian propositions. Therefore, an advocate of the naive version of the Multiple Relation Theory cannot simply reject Frege's constraint, and, instead, accept a version of Frege's constraint for propositional modes of presentation.

We see that it is very likely that within the naive version of the Multiple Relation Theory the solution to Schiffer's puzzle can neither be to reject the special-case consequence nor to reject Frege's constraint. In other words, the naive version of the Multiple Relation Theory has to provide an explanation of how both (27) and (28) can be true, although Peter is both a brilliant logician and fully rational. Since neither $R_{(b e l, 3)}$, nor Ralph, nor the property of being Polish, nor Karol Wojtyła is presented to Peter by two modes of presentation without him recognising that these are modes of presentation of one and the same object/property/relation, it is very unclear whether the naive version of the Multiple Relation Theory can explain this. An advocate of the Multiple Relation could respond that this only shows that we have to reject the naive version of the Multiple Relation Theory, and, instead, accept the contextualist version of the Multiple Relation Theory. However, next, I will argue with new Schiffer cases that even the contextualist version of the Multiple Relation Theory leads to instances of the problem of rationality regarding de re belief that violate Frege's constraint. This will undermine the Multiple Relation Theory in general.

\section{Schiffer's puzzle again}

According to the contextualist version of the Multiple Relation Theory, the modes of presentation implied by $\left(M^{\prime}\right)$ are simply the modes of presentation implied by Frege's constraint. Otherwise, the contextualist version of the Multiple Relation Theory could not explain that both (4) and (5) can be true of a rational logician like Ralph.

(4) Ralph believes that Karol Wojtyła is Polish.

(5) Ralph disbelieves that John Paul II. is Polish.

According to $\left(M^{\prime}\right),(4)$ has the logical form in (10), and (5) has the logical form in (29), where $T_{K W}$ and $T_{K W}^{\prime}$ are two distinct (contextually determined) (types of) modes of presentation of Karol Wojtyła.

(10) $R_{(b e l, 3)}$ (Ralph, $\left\langle\lambda x\left[x\right.\right.$ is Polish], $\left.T_{P o l}\right\rangle$, $\left\langle\right.$ Karol Wojtyła, $\left.\left.T_{K W}\right\rangle\right)$.

(29) $R_{(d i s, 3)}$ (Ralph, $\left\langle\lambda x[x\right.$ is Polish $\left.], T_{P o l}\right\rangle$, $\left\langle\right.$ Karol Wojtyła, $\left.T_{K W}^{\prime}\right\rangle$ ). 
Now, in order to explain that both (10) and (29) can be true of a rational logician like Ralph, an advocate of the contextualist version of the Multiple Relation Theory is committed to the claim that Ralph does not recognise that $T_{K W}$ and $T_{K W}^{\prime}$ are modes of presentation of one and the same person. Since this is tantamount to saying that the modes of presentation implied by (10) and (29) play the role defined by Frege's constraint, it follows that according to the contextualist version of the Multiple Relation Theory the modes of presentation implied by $\left(M^{\prime}\right)$ are simply the modes of presentation implied by Frege's constraint.

Both $\left(M^{\prime}\right)$ and Frege's constraint leave open what modes of presentation are. In this section, I will discuss the three main conceptions of the modes of presentation implied by $\left(M^{\prime}\right)$ (and Frege's constraint), and I will argue that, ultimately, on all three conceptions $\left(M^{\prime}\right)$ leads to instances of the problem of rationality that violate Frege's constraint. This will suggest that also the contextualist version of the Multiple Relation Theory does not provide a solution to Schiffer's puzzle.

A first construal of the modes of presentation implied by $\left(M^{\prime}\right)$ and Frege's constraint could be that the modes of presentation implied by $\left(M^{\prime}\right)$ and Frege's constraint are expressions of a public language. According to such a construal of the modes of presentation implied by $\left(M^{\prime}\right)$ and Frege's constraint, (4) has to be analysed as (30), and (5) has to be analysed as (31), where the two public language names 'Karol Wojtyła' and 'John Paul II.' are the ways Karol Wojtyła is presented to Ralph.

(30) $R_{(b e l, 3)}$ (Ralph, $\langle\lambda x[x$ is Polish], ' $x$ is Polish' $\rangle,\langle$ Karol Wojtyła, 'Karol Wojtyła' $\rangle$ ).

(31) $R_{(\text {dis,3) }}$ (Ralph, $\langle\lambda x[x$ is Polish], ' $x$ is Polish' $\rangle$, 〈Karol Wojtyła, 'John Paul II.' $\rangle)$.

Since, in the above example, Ralph does not recognise that 'Karol Wojtyła' and 'John Paul II.' are names of one and the same person, prima facie, expressions of a public language seem to be good candidates for the role defined by Frege's constraint. However, in connection with Kripke's Paderewski example (Kripke 1979, pp. 265-266), such a conception of the modes of presentation implied by Frege's constraint reaches its limits; i.e. it leads to an instance of the problem of rationality regarding de re belief that violates Frege's constraint.

In Kripke's Paderewski example, Kripke's Peter gets introduced twice to one and the same name 'Paderewski' without him recognising it. Therefore, even as a brilliant and fully rational logician Peter could sincerely and reflectively utter both (32) and (33).

(32) Paderewski has musical talent.

(33) It is not the case that Paderewski has musical talent.

However, according to the public language conception of the modes of presentation implied by Frege's constraint, there would be a mode of presentation $m$ such that Paderewski is both believed and disbelieved by Peter to have musical talent under $m$; i.e. the public language name 'Paderewski'. Thus, on the public language conception of the modes of presentation implied by Frege's constraint, Kripke's example would lead to an instance of the problem of rationality that violates Frege's constraint. 
Following Kripke's Paderewski example, an advocate of the contextualist version of the Multiple Relation Theory could claim that, instead of expressions of a public language, the modes of presentation implied by $\left(M^{\prime}\right)$ and Frege's constraint are bundles of properties or files of information. ${ }^{19}$ For example, it is very likely that in Kripke's example Peter has two distinct files of information of Paderewski; one file containing, among others, the information being a politician, and one file containing, among others, the information being a musician. Following this, an advocate of the contextualist version of the Multiple Relation Theory could claim that since Paderewski is believed by Peter to have musical talent under one file, and disbelieved by Peter to have musical talent under the other file, without him recognising that these are files of one and the same person, Peter cannot be convicted of irrationality. However, even on the files of information conception of the modes of presentation implied by $\left(M^{\prime}\right)$ the contextualist version of the Multiple Relation Theory leads to instances of the problem of rationality that violate Frege's constraint.

Assume that although Harry has two names for Cicero in his public language, he has only one file of information of Cicero; i.e. the file containing the information being a Roman orator, being named 'Cicero', and being named 'Tully' ${ }^{20}$ Thus, although Harry has two names for Cicero, he associates one and the same information with 'Cicero' and 'Tully'. Nevertheless, Harry could accept 'Cicero was a Roman' without being disposed to accept 'Tully was a Roman'; i.e. if Harry is irrational or not very reflective. Moreover, following this, a rational, normal English speaker like Sally could be disposed to sincerely and reflectively utter (34) and (35) even if she knows both that 'Cicero = Tully' is true and that Harry associates one and the same file of information with 'Cicero' and 'Tully'; e.g. if Sally has strong sententialist intuitions. ${ }^{21}$

(34) Harry believes that Cicero was a Roman.

(35) Harry does not believe that Tully was a Roman.

Together with $(D P)$ and $\left(D P^{\prime}\right)$, it would follow that both (36) and (37) are true.

(36) Sally believes that Harry believes that Cicero was a Roman.

(37) Sally disbelieves that Harry believes that Tully was a Roman.

If (36) and (37) are true, then, according to the special-case consequence, so are (38) and (39).

(38) Cicero is believed by Sally to be someone such that Harry believes that he was a Roman.

(39) Tully is disbelieved by Sally to be someone such that Harry believes that he was a Roman.

\footnotetext{
19 See for example Recanati's theory of mental files (Recanati 2012).

20 We could even assume that Harry never distinguished between two Cicero files in the past. For example, we could assume that Harry got the information by reading a book, where it was written that Cicero was a Roman orator who is also called 'Tully'.

${ }^{21}$ With sententialist intuitions I mean that Sally thinks that a sentence of the form ' $A$ believes that $S$ ' is true if and only if the referent of $A$ believes the sentence $S$ to be true, or at least that she has intuitions that would be in accordance with such an analysis of belief ascriptions.
} 
However, since Sally knows that Harry associates one and the same file of information with 'Cicero' and 'Tully', according to the file of information conception of the modes of presentation implied by $\left(M^{\prime}\right)$, (38) has the logical form in (40), and (39) has the logical form in (41), where $F_{\text {Cicero }}$ is the Cicero file that Sally attributes to Harry. $^{22}$

(40) $B E L$ (Cicero, Sally, $\lambda z\left[R_{(b e l, 3)}\left(\right.\right.$ Harry, $\left\langle\lambda x\left[x\right.\right.$ was a Roman], $\left.T_{R o m}\right\rangle,\langle z$, $\left.\left.\left.F_{\text {Cicero }}\right\rangle\right)\right]$ ).

(41) DIS (Cicero, Sally, $\lambda z\left[R_{(b e l, 3)}\left(\right.\right.$ Harry, $\left\langle\lambda x[x\right.$ was a Roman $\left.], T_{R o m}\right\rangle,\langle z$, $\left.\left.\left.F_{\text {Cicero }}\right\rangle\right)\right]$ ).

From this, in turn, it would follow together with Frege's constraint that Cicero is presented to Sally by two modes of presentation without her recognising that these are modes of presentation of one and the same person. ${ }^{23}$ However, since Sally knows that 'Cicero = Tully' is true, we can simply assume that Cicero is not presented to Sally by two modes of presentation without her recognising that these are modes of presentation of one and the same person. It follows that on the files of information conception of the modes of presentation implied by $\left(M^{\prime}\right)$ the contextualist version of the Multiple Relation Theory leads to instances of the problem of rationality regarding de re belief that violate Frege's constraint.

An advocate of the contextualist version of the Multiple Relation Theory could respond that this only shows that in the above example the modes of presentation implied by $\left(M^{\prime}\right)$ are expressions of a public language; i.e. that (38) has to be analysed as (42), and that (39) has to be analysed as (43), where the two names 'Cicero' and 'Tully' play the role of the modes of presentation that Sally attributes to s Harry.

(42) $B E L$ (Cicero, Sally, $\lambda z\left[R_{(b e l, 3)}\left(\right.\right.$ Harry, $\left\langle\lambda x\left[x\right.\right.$ was a Roman], $\left.T_{R o m}\right\rangle,\langle z$, 'Cicero' $\rangle)])$.

(43) DIS (Cicero, Sally, $\lambda z\left[R_{(b e l, 3)}\right.$ (Harry, $\left\langle\lambda x\left[x\right.\right.$ was a Roman], $\left.T_{R o m}\right\rangle,\langle z$, 'Tully'〉)]).

However, we have seen that such a public language conception of the modes of presentation implied by $\left(M^{\prime}\right)$ does not provide a solution to Kripke's Paderewski example. Therefore, such a solution to the Cicero/Tully example would commit an advocate of $\left(M^{\prime}\right)$ to a mixed view regarding the modes of presentation implied by $\left(M^{\prime}\right)$; i.e. that

\footnotetext{
22 Note that according to the file of information conception of the modes of presentation implied by $\left(M^{\prime}\right)$, the contextually determined file of Sally's utterance of (34) has to be the file that Harry associates with his uses of 'Cicero', and the contextually determined file of Sally's utterance of (35) has to be the file that Harry associates with his uses of 'Tully'. Otherwise, it would be very unclear what it means to be a contextually determined mode of presentation according to the file of information conception of the modes of presentation implied by $\left(M^{\prime}\right)$. Thus, since Harry associates one and the same file of information with 'Cicero' and 'Tully', according to the file of information conception of the modes of presentation implied by $\left(M^{\prime}\right)$, the contextually determined file of Sally's utterance of (34) is simply the contextually determined file of Sally's utterance of (35); i.e. $F_{\text {Cicero }}$.

${ }^{23}$ Note that here we do not apply Frege's constraint to Harry's beliefs, but to Sally's beliefs. Since, unlike Harry, Sally is rational, from (40) and (41) it follows together with Frege's constraint that Cicero is presented to Sally by two modes of presentation without her recognising that these are modes of presentation of one and the same person.
} 
the modes of presentation implied by $\left(M^{\prime}\right)$ are sometimes files of information, like in Kripke's Paderewski example, and sometimes expressions of a public language, like in the Cicero/Tully example, however, as we have seen above, according to the contextualist version of the Multiple Relation Theory, the modes of presentation implied by $\left(M^{\prime}\right)$ are simply the modes of presentation implied by Frege's constraint. Since it is very unlikely that the functional role defined by Frege's constraint is sometimes played by public language expressions, and sometimes played by files of information, also a mixed view of the modes of presentation implied by $\left(M^{\prime}\right)$ is not very plausible. This suggests that within the contextualist version of the Multiple Relation Theory the solution to the Cicero/Tully example cannot simply be to analyse (38) as (42) and (39) as (43).

In light of this, an advocate of the contextualist version of the Multiple Relation Theory could claim that, instead of public language expressions or files of information, the modes of presentation implied by $\left(M^{\prime}\right)$ are expressions of a language of thought $L O T$. For example, an advocate of the contextualist version of the Multiple Relation Theory could claim that although Kripke's Peter does not have two names for Paderewski in his public language, he has two names for Paderewski in his language of thought. Prima facie, the same could be said of Harry; i.e. that although Harry has only one file of information of Cicero, just like he has two names for Cicero in his public language, he also has two names for Cicero in his language of thought. However, as Braun (1998, fn 39) points out, in connection with Kripke's Paderewski example such a solution presupposes that the language of thought is not the public language; i.e. English. Otherwise, Peter would also have only one name for Paderewski in his language of thought. But then from the fact that Harry has two names for Cicero in his public language it does not automatically follow that he also has two names for Cicero in his language of thought. On the contrary, if Harry's language of thought is not English, then, since Harry never distinguished two mental files of Cicero, it is very likely that he also never distinguished two mental names of Cicero. This suggests that in connection with the Harry/Sally example the LOT conception of the modes of presentation implied by $\left(M^{\prime}\right)$ leads to a similar problem as the file of information conception of the modes of presentation implied by $\left(M^{\prime}\right)$.

We see that on the three main conceptions of the modes of presentation implied by $\left(M^{\prime}\right)$ and Frege's constraint also the contextualist version of the Multiple Relation Theory leads to instances of the problem of rationality regarding de re belief that violate Frege's constraint. This suggests that, just like the naive version of the Multiple Relation Theory, ultimately, also the contextualist version of the Multiple Relation Theory does not provide a solution to Schiffer's puzzle. This undermines the Multiple Relation Theory in general.

\section{Conclusions}

Unlike the naive version of the direct-reference theory of belief reports, the naive version of the Multiple Relation Theory, i.e. $(M)$, seems to be committed to both the special-case consequence and Frege's constraint. Since, together with the specialcase consequence and Frege's constraint, the naive version of the Multiple Relation 
Theory leads to contradictions, this undermines the naive version of the Multiple Relation Theory. This was Schiffer's puzzle. Moreover, even if the naive version of the Multiple Relation Theory is not committed to both the special-case consequence and Frege's constraint, it has to provide an explanation of how both (27) and (28) can be true, although Peter is both a brilliant logician and fully rational. Since neither $R_{(b e l, 3)}$, nor Ralph, nor the property of being Polish, nor Karol Wojtyła is presented to Peter by two modes of presentation without him recognising that these are modes of presentation of one and the same object/property/relation, it is very unclear how the naive version of the Multiple Relation Theory could explain this.

In order to solve Schiffer's puzzle, an advocate of the Multiple Relation Theory could reject the naive version of the Multiple Relation Theory, and, instead, accept the contextualist version of the Multiple Relation Theory; i.e. $\left(M^{\prime}\right)$. However, as we have seen in Sect. 5, just like the naive version of the Multiple Relation Theory, also the contextualist version of the Multiple Relation theory leads to instances of the problem of rationality regarding de re belief that violate Frege's constraint. Therefore, Schiffer's puzzle not only undermines the naive version of the Multiple Relation Theory, but the Multiple Relation Theory in general.

For advocates of the Multiple Relation Theory, a possible way out of the problem is to claim with Jubien (2001) that the relata of the belief relation are always properties and relations; i.e. that there is nothing like de re belief, and, therefore, that there is nothing like the problem of rationality regarding de re belief or Schiffer's puzzle. However, most advocates of the Multiple Relation Theory hold that, in addition to properties and relations, also individuals can be the relata of the belief relation.

Another possibility would be to distinguish between the assertoric content of a sentence (what we say with an utterance of the sentence) and its semantic content (the meaning of the sentence). Following this, an advocate of the Multiple Relation Theory could claim that $(M)$ and $\left(M^{\prime}\right)$ are theories of assertoric content, and not theories of semantic content. Therefore, the solution to Schiffer's puzzle goes, although a speaker who accepts (4) and (12) both believes and disbelieves one and the same assertoric objects, he cannot be convicted of irrationality, since the sentences he thereby uses do not have the same semantic content. However, in order to offer a complete solution to Schiffer's puzzle, such a theory would have to say what the semantic content of sentences like (4) and (8) is, and how sentences like (4) and (8) can have different semantic contents.

Another possible way out of Schiffer's puzzle would be to claim with Neo-Russellians, like Salmon (1986, 2006) and Braun (1998, 2006), that a sentence like (1) does not have the logical form in (2a), but rather the logical form in (2b). Following this, one could argue with Salmon that Schiffer's puzzle provides a counter-instance of $(S)$, and, therefore, does not lead to instances of the problem of rationality regarding de re belief that violate Frege's constraint. However, in (Rinner 2020), I argue that although the naive version of the direct-reference theory of belief reports advocated by Salmon and Braun is not committed to $(S)$, it nevertheless leads to instances of the problem of rationality regarding de re belief that violate Frege's constraint. Since the same problem does not arise for the contextualist version of the direct-reference theory of belief reports advocated, among others, by Crimmins and Perry (1989) and 
Crimmins (1992), unlike the naive version, the contextualist version of the directreference theory of belief reports would still provide a solution to Schiffer's puzzle.

Acknowledgements Open Access funding provided by Projekt DEAL. I would like to thank Hannes Leitgeb and three anonymous reviewers for their helpful comments on earlier drafts of the paper. This work was generously supported by the Fritz Thyssen Stiftung (Resesarch Stipend).

Open Access This article is licensed under a Creative Commons Attribution 4.0 International License, which permits use, sharing, adaptation, distribution and reproduction in any medium or format, as long as you give appropriate credit to the original author(s) and the source, provide a link to the Creative Commons licence, and indicate if changes were made. The images or other third party material in this article are included in the article's Creative Commons licence, unless indicated otherwise in a credit line to the material. If material is not included in the article's Creative Commons licence and your intended use is not permitted by statutory regulation or exceeds the permitted use, you will need to obtain permission directly from the copyright holder. To view a copy of this licence, visit http://creativecommons.org/licenses/by/4.0/.

\section{References}

Boër, S. E. (2002). On the multiple relation theory of judgement. Erkenntnis, 56, 181-214.

Braun, D. (1998). Understanding belief reports. Philosophical Review, 107, 555-95.

Braun, D. (2006). Illogical, but rational. Nô̂s, 40, 376-79.

Crimmins, M. (1992). Talk about beliefs. Cambridge, MA: MIT Press.

Crimmins, M., \& Perry, J. (1989). The prince and the phone booth: Reporting puzzling beliefs. The Journal of Philosophy, 86, 685-711.

Donnellan, K. (1970). Proper names and identifying descriptions. Synthese, 21, 335-358.

Kaplan, D. (1989). Demonstratives. In J. Almog, H. Wettstein, \& J. Perry (Eds.), Themes from Kaplan (pp. 481-563). Oxford: Oxford University Press.

Hanks, P. (2007). How Wittgenstein defeated Russell's multiple relation theory of judgment. Synthese, 154, $121-46$.

Jubien, M. (2001). Propositions and the objects of thought. Philosophical Studies, 104, 47-62.

Kripke, S. (1979). A puzzle about belief. In A. Margalit (Ed.), Meaning and use (pp. 239-83). Dordrecht: Reidel.

Kripke, S. (1980). Naming and necessity. Oxford: Blackwell.

Lebens, S. (2017). Bertrand Russell and the nature of propositions: A history and defence of the multiple relation theory of judgement. New York: Routledge.

Marcus, R. B. (1961). Modalities and intensional languages. Synthese, 13, 303-322.

Moltmann, F. (2003). Propositional attitudes without propositions. Synthese, 135, 77-118.

Moltmann, F. (2013). Abstract objects and the semantics of natural language. Oxford: Oxford University Press.

Moltmann, F. (2017). Cognitive products and the semantics of attitude verbs and deontic modals. In F. Moltmann \& M. Textor (Eds.), Act-based conceptions of propositional content. Contemporary and historical contributions. Oxford: Oxford University Press.

Newman, A. (2002). The correspondence theory of truth. Cambridge: Cambridge University Press.

Oliver, A., \& Smiley, T. (2004). Multigrade predicates. Mind, 113, 609-81.

Perry, J. (1977). Frege on demonstratives. Philosophical Review, 86, 474-497.

Recanati, F. (2012). Mental files. Oxford: Oxford University Press.

Rinner, S. (2020). Naive Russellians and Schiffer's puzzle. Erkenntnis,. https://doi.org/10.1007/s10670020-00218-3.

Russell, B. (1905). On denoting. Mind, 14, 479-493.

Russell, B. (1910-1911). Knowledge by acquaintance and knowledge by description. Proceedings of the Aristotelian Society, 11, 108-128.

Russell, B. (1912). The problems of philosophy. Oxford: Oxford University Press.

Russell, B. (1913). Theory of knowledge. London: Routledge.

Russell, B. (1918). Lectures on logical atomism. In R. Marsh (Ed.), Logic and knowledge (p. 1956). London: Allen and Unwin. 
Salmon, N. (1986). Frege's puzzle. Cambridge, MA: MIT Press.

Salmon, N. (2006). The resilience of illogical belief. Noûs, 40, 369-75.

Salmon, N. (2011). A note on Kripke's puzzle about belief. In A. Berger (Ed.), Saul Kripke (pp. 235-252). Cambridge: Cambridge University Press.

Schiffer, S. (2006). A problem for a direct-reference theory of belief reports. Noûs, 40, 361-68.

Publisher's Note Springer Nature remains neutral with regard to jurisdictional claims in published maps and institutional affiliations. 